\title{
The Single-board Computer As a Toll to Measure the Weather Parameters in the Marine Areas
}

\author{
T. Neumann \\ Gdynia Maritime University, Gdynia, Poland
}

\begin{abstract}
This paper is an analysis of the possibilities of using a Raspberry Pi microcomputer on a ship. The paper is an introduction characterizing the project goal and its main assumptions. It includes a brief history of shipping development and the current use of computer systems on board merchant ships. Also meteorological devices have been characterized that can be used on the ship to obtain weather data. The paper also includes description of the Raspberry Pi microcomputer, its specification and operating systems on which the device works. The project of a station is designed to measure the value of air and water temperature, humidity and atmospheric pressure.
\end{abstract}

\section{INTRODUCTION}

This paper is an analysis of the possibilities of using a Raspberry Pi microcomputer on board a ship. The main purpose of this paper is to find the possibility of using this device to displace current traditional measuring devices. The measurement data are to be as close as possible to the values obtained by such devices. The goal is also the development of ship technology and finding a solution that allows it to be used in all possible situations, such as power failures. [1]

The first part of the work presents an analysis of the use of computer systems on operational ships, attention will be paid to the use of traditional measuring devices in the aspect of meteorological measurements. Measuring devices and their operating ranges will be presented. An aspect of the use of this data by officers and mechanics during the operation of merchant ships will be presented.

The next part will present the Raspberry $\mathrm{Pi}$ microcomputer, its technical data and operating systems on which the device works. In addition, the Python programming language will be presented. This language will be needed to create a code that will read data from meteorological station sensors and display ready values of temperatures, atmospheric pressure and humidity.

The last part of the work is a project to build a meteorological station on a merchant ship. First, the sensors used, their dimensions and methods of connecting to the microcomputer will be presented. Then, by using ready-made scripts for individual sensors, the first measurements will be presented. Scripts should be programmed to display both sensor values simultaneously. The values will be presented by calling the code to minimize the use of microcomputer resourses. 
Meteorology is the science that deals with the study of physical phenomena and processes occurring in the atmosphere, in particular in its lowest layer - the troposphere. These processes affect how the weather and climate in a given area are shaped. Meteorological conditions play an important role in maritime transport, where not only sailing time matters, but also the safety of crew and ship. The officer must take into account factors such as the state of the sea, visibility, tide level, temperature, currents and even the presence of ice cream in a given area, both when planning the ship's route and conducting the watch. Constant observation of these factors on the bridge is therefore crucial if we want to carry out a ship from one port to another without problems, especially if the journey is counted in weeks. [2]

The main source of valuable information about the weather on the ship are primarily visual observations conducted by an officer or a watchman. Skillful assessment of the state of the sea, wave height and visibility allows a sufficient level to determine the prevailing weather and often how it will shape over the next few hours.

A hygrometer, i.e. an instrument constructed of a dry and wet thermometer, is increasingly used to measure the temperature on a ship. This instrument is often placed on both wings of the sternum. Based on the temperature differences indicated by both thermometers, we can read the value of relative humidity from special tables or psychometric charts.

In order to determine the wind speed and its direction, a sailor may suggest the state of the sea and its surface, in addition most ships are equipped with a device called an anemometer, which measures the speed of air, gas and liquid flow. The most common solution is a portable anemometer, although wind gauges are being installed more and more often on ships, sending information about wind speed and direction remotely to devices on the bridge.

The device for measuring atmospheric pressure is a barometer. Depending on the principle of operation, we distinguish a liquid and spring barometer, the so-called aneroid, which is most often placed on the ship's bridge. Rapid changes in pressure often correlate with occurring weather changes. Low pressure is often associated with adverse weather phenomena such as typhoons and hurricanes. High, in turn, is usually hightemperature, sunny weather. At sea level, the average atmospheric pressure is $1013 \mathrm{hPa}$. [3]

Observation of the cloud cover is not the most difficult tasks when the sky is clear or completely covered with clouds. However, the ability to identify clouds in the sky is useful when it is partly cloudy. Knowing the characteristics of the precipitation of a given cloud, we are able to determine whether, for example, planned painting work on board can be interrupted by the coming rain and make the right decision. [4,5]
The history of merchant ships goes back to ancient centuries. Ancient Greeks and Romans aboard their ships carried out trade expeditions throughout the Mediterranean, as well as nearby waters accessible to their ships. They were built of wood, and used their sails or the strength of human muscles for their motive power. The operation of ships consisted mainly of sailing with a given commodity to a specific port where it was sold and new buyers were gained. Navigation was mainly based on sailing on known seas and routes. There were no maps, so the position of the ship could not be determined. Over the years, the appearance, characteristics and capabilities of ships have changed. Crossing oceans and discovering the world began. Discoverers such as Christopher Columbus and Ferdinand Magellan have reached new previously unknown lands. In 1110, magnetic compasses appeared, which began to determine directions, and one hundred and sixty years later in 1270, the first maps appeared. [6] At the end of the nineteenth century, units made of concrete and then of steel began to arise. The first units received steam engines, and transatlantic journeys became commonplace. However, it has only been in the last few decades that ships have received something that officers and mechanics owe to easier, safer and more effective work. They are computing, monitoring and alarming systems based on computer networks.[7]

Such networks allow a deeper understanding of the processes occurring in individual devices. On the hull, in ballast and fuel tanks, in the main engine and many other locations there are sensors constantly monitoring parameters, which are transmitted to the main unit, which thanks to computer systems connected to the ship's network transmits current data.

\section{RASPBERRY PI - MICROCOMPUTER'S SPECIFICATION}

Technological progress has developed significantly over the last several years. The equipment available on the market now, compared to that of the early $90 \mathrm{~s}$ of the last century, is huge. Not only in terms of materials and the availability of such devices, but primarily due to the computational capabilities and their sizes. The first computer created during the war called ENIAC (Electronic Numerical Integrator And Computer) had an area of 140 square meters, i.e. a medium-sized single-family house. His computational abilities allowed for basic calculations related to military subjects. The computer was mainly used for ballistic and nuclear weapons calculations. [8]

Over time, computers have become smaller and more accessible to ordinary users. Home and personal computers were created, followed by notebooks. However, a very important date in the history of personal computers was February 29, 2012. That day, the smallest computer, the Raspberry Pi microcomputer, went on sale (see Fig. 1). It was designed by the Raspberry Pi foundation, located at 
the University of Cambridge. Its main chairman is Eden Upton, who is still trying to improve this microcomputer so that he can accommodate the most efficient components in its small dimensions. [9]

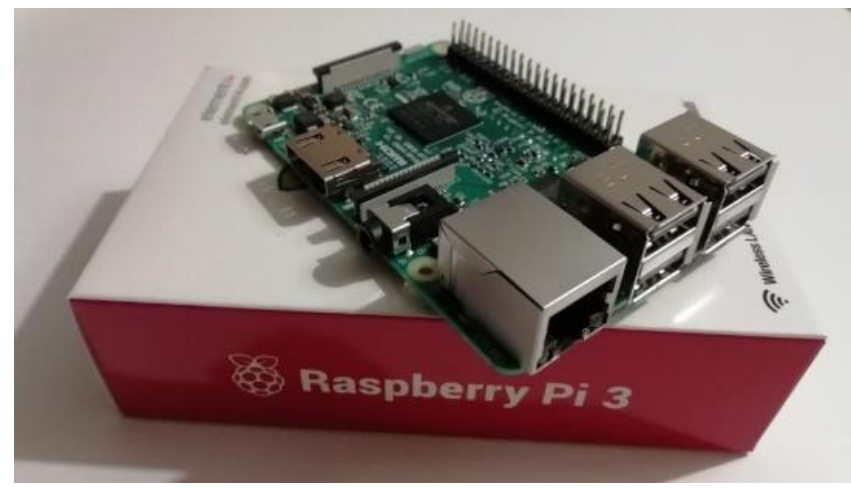

Figure 1. Raspberry Pi 3 B

The technical specification of the device based on materials obtained from the microcomputer manual and the website of the Polish distributor will be presented below. The presented model is one of the basic manufacturer, and the data may vary depending on the version selected.

Table 1. Specifications of Raspberry Pi 3 B device

\begin{tabular}{ll}
\hline Raspberry & Pi 3 model B \\
Processor & Broadcom BCM2837 64-bit \\
Core & Quad-Core ARM Cortex A53 \\
Operating system & Linux Raspbian \\
CPU clock speed & 1,2 GHz \\
Architecture & ARMv8-A \\
RAM & 1GB LPDDR2 @ 900 MHz \\
Memory & microSD card \\
GPIO Socket & Connector 40-pin (2x20) raster 2,54mm \\
Power & 5 V / 2 A microUSB input \\
Dimensions & 85x56x17 mm \\
USB interface & 4x USB2.0 gniazdo typ A \\
Network interface & Port Ethernet 10/100 Mbps \\
WiFi interface & 802.11 b/g/n 150 Mbps \\
Bluetooth & BLE 4.1 \\
\hline
\end{tabular}

As you can see in the table above, despite the small dimensions, the components contained in the device allowed to create a microcomputer with very interesting parameters. It is worth adding that the computer has an additional WiFi and Bluetooth interface.

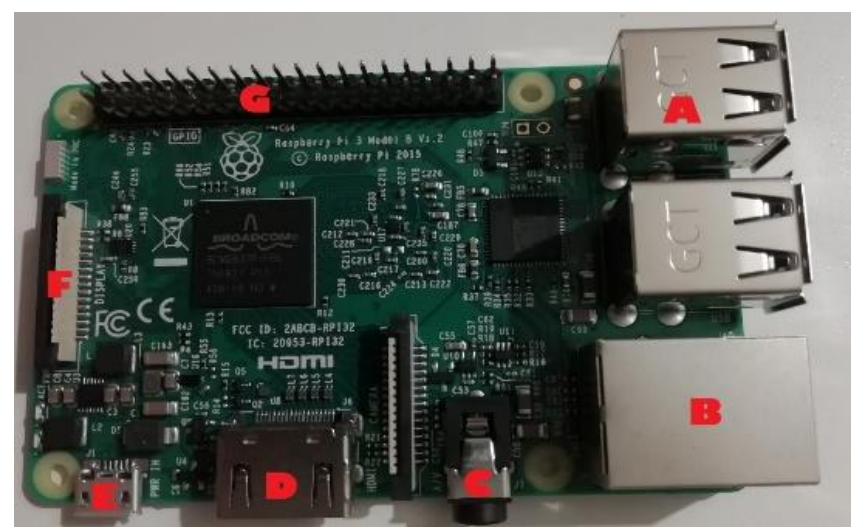

Figure 2. Outputs and inputs in Raspberry Pi 3 B
Inputs and outputs available on the Raspberry Pi 3 B microcomputer (see Fig. 2): [10]

- A. USB port - 4 USB 2.0 ports allowing you to connect external entities such as an external disk, pendrive, ROM etc. However, due to the low power consumption, by the microcomputer itself, USB sockets offer lower power than standard sockets in personal computers

- B. Ethernet port - standard input for local networks, so-called cable connection with RJ45 plug. It allows you to connect the microcomputer to a wider computer network.

- C. Video Composite RCA output - analog video signal output. The signal is sent in NTSC or PAL formats. The quality of the transmitted image is a maximum of $480 \mathrm{i}$ or SD (Standard-Definition).

- D. HDMI output - interface for sending video and audio in a digital form. The sent image can be in UHD (Ultra High Definition) format, i.e. $4 \mathrm{~K}$. It can be used when using a microcomputer as, among others multimedia platform.

- E. Power socket - microUSB input, identical to mobile phones, $5 \mathrm{~V} / 2 \mathrm{~A}$.

- F. DSI 15-pin socket - the last available video output on the board, commonly used for connecting LCD monitors.

- G. GPIO port - 40 pins for connecting peripheral devices to the microcomputer. They can be both input and output devices.

There is also one slot on the other side of the main board under the DSI socket (see point F) and is used to support microSD cards. This is an important socket due to the characteristics of the device, which, having a very small internal memory, does not have an operating system installed. Therefore, it is important for the device to have a microSD card with the operating system installed before it is turned on. It will also allow you to operate easily between different operating systems, only by changing the microSD card.

Due to the use of GPIO sockets in the rest of the work, it is important to provide their specifications (see Fig. 3).

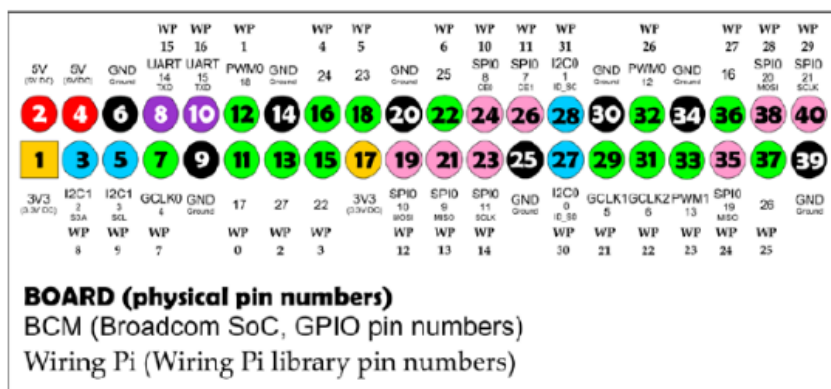

Figure 3. Specification of GPIO sockets

Due to the adaptation of the device primarily to programming, the operating system, which used in the microcomputer must allow it to delve into its source code. Unfortunately, the most popular Windows or macOS available on the market are closed-source systems. This means that it is kept secret and no one except the creators knows what is inside it. Free and open source is the English term for free systems that provide users with the ability to view and modify such code. [11] 


\section{USE OF RASPBERRY PI}

In the previous chapter, the Raspberry Pi microcomputer was presented, which was used to create a weather station that is the goal of this thesis. The weather station aims to measure basic weather parameters that are needed to control the weather situation and create entries in the ship's logbook. The values are to be presented on one screen, refreshing the displayed values every minute. This will allow you to collect current information. [12]

Parameters presented by the weather station:

- Air temperature

- Water temperature

- Atmospheric pressure

- Air humidity

Wind strength and direction will not be represented by the weather station. These parameters are needed for safe navigation, their value must be very accurate, and also be presented on several devices at the same time. In addition, wind gusts should be presented on an ongoing basis, which is difficult to present based on basic sensors available to a wide range of users, and additionally available for connection to a microcomputer. It would also be necessary to connect a gyro-compass / magnetic compass and a log to determine the actual wind from the apparent wind value represented by the anemometer. The weather station I created is designed to present weather information on one small screen located at the table with the ship's logbook. [13]

The station was created by connecting to a Raspberry Pi microcomputer by more specifically to GPIO sockets BME280 and DS18B20 sensors. The first is a sensor for air temperature, atmospheric pressure and humidity. The second is a waterproof probe for measuring water temperature. The specifications of both sensors are provided in the table below.

Table 2. Specification of weather station sensors

\begin{tabular}{lll}
\hline Parameter & BME280 & DS18B20 \\
Interface & SPI/ I2C & $1-$ wire (GPIO) \\
Temperature range & $-40^{\circ} \mathrm{C}-85^{\circ} \mathrm{C}$ & $-55^{\circ} \mathrm{C}-125^{\circ} \mathrm{C}$ \\
Pressure range & $300 \mathrm{hPa}-1100 \mathrm{hPa}$ & --- \\
Humidity range & $0 \% \mathrm{RH}-100 \% \mathrm{RH}$ & --- \\
Temperature accuracy $+/-1^{\circ} \mathrm{C}$ & $+/-0,5^{\circ} \mathrm{C}$ \\
Pressure accuracy & $+/-1 \mathrm{hPa}$ & -- \\
Humidity accuracy & $+/-3 \% \mathrm{RH}$ & -- \\
Power & $3,3 \mathrm{~V}$ & $3,0 \mathrm{~V}$ \\
Dimensions & $27 \times 20 \mathrm{~mm}$ & $6 \times 51 \mathrm{~mm}$ \\
Cable length: & & $1 \mathrm{~m}$ \\
\hline
\end{tabular}

As you can see in the table above, these sensors are very small in size, which allows them to be installed anywhere outside the ship, as well as their voltage consumption allows you to connect them and the microcomputer to a standard power outlet. The sensor ranges are very wide and sufficient for secure weather forecasting. Regarding accuracy, the values presented by the DS18B20 are small and the maximum discrepancy is $+/-0.5{ }^{\circ} \mathrm{C}$. The BME280 sensor is a little less accurate, but they still show sufficient values for the weather station being built. Both sensors are basic devices widely available on the market, therefore their accuracy difference is not minimal. If the idea was used in maritime economy, the sensors could become very accurate, additionally supervised by meteorological institutions.

The first sensor to be connected is BME280. It operates on the I2C interface, so it is important to properly connect the wires from the sensor to the GPIO sockets in the microcomputer. The photo below shows how to connect the sensor to the microcomputer.

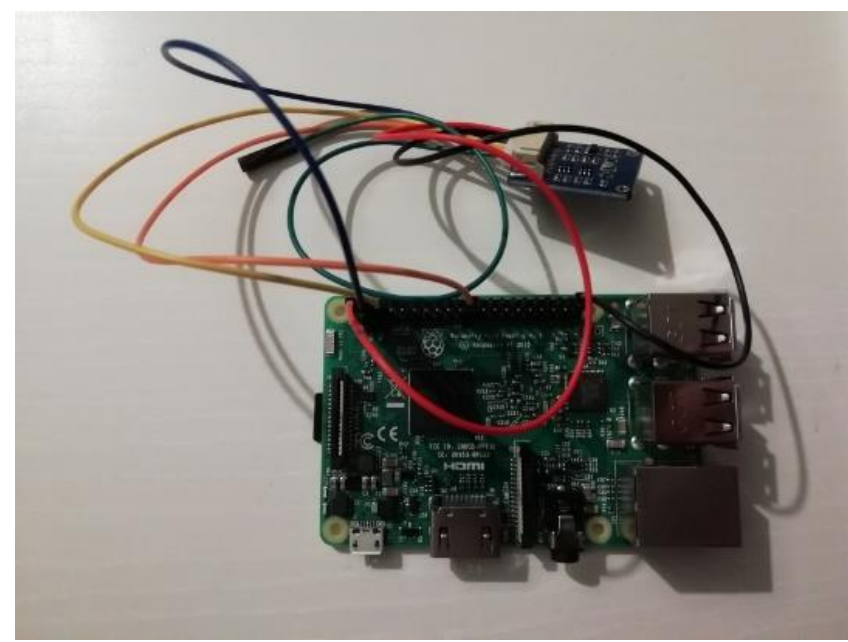

Figure 4. BME280 sensor connected to the microcomputer

After connecting the sensor to the microcomputer, the next step was to connect the Raspberry Pi to the power supply and the screen on which the measurement results could be displayed. Connecting the sensor itself will not display the measurement results on the screen, which is why a ready-made script prepared by the creator of the Waveshare BME280 sensor was used. The code fragment is presented below, it is forcing the presentation of temperature, pressure and humidity values.

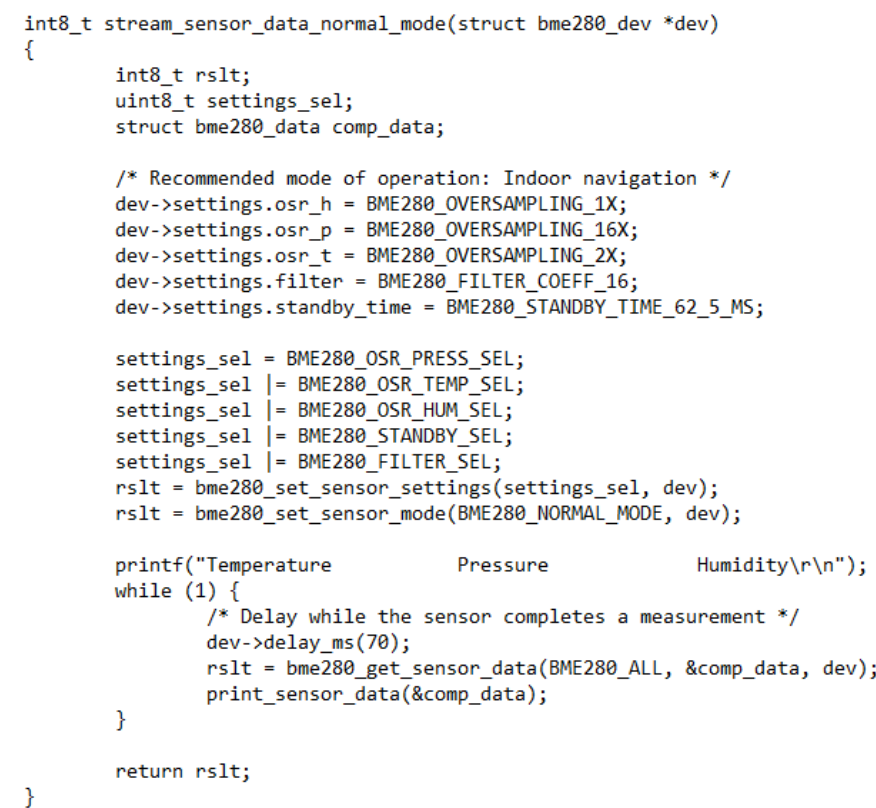

Figure 5. Used Python Code Fragments

The code is assumed to display values on one line with a refresh period of microseconds. It is quite frequent to receive measurement results, but the user 
can control the functioning of the sensor, thanks to which we can check whether the impact of external objects can affect the result. For example, placing a heat source on the sensor should increase the temperature or placing the sensor near a water source will change the humidity value.

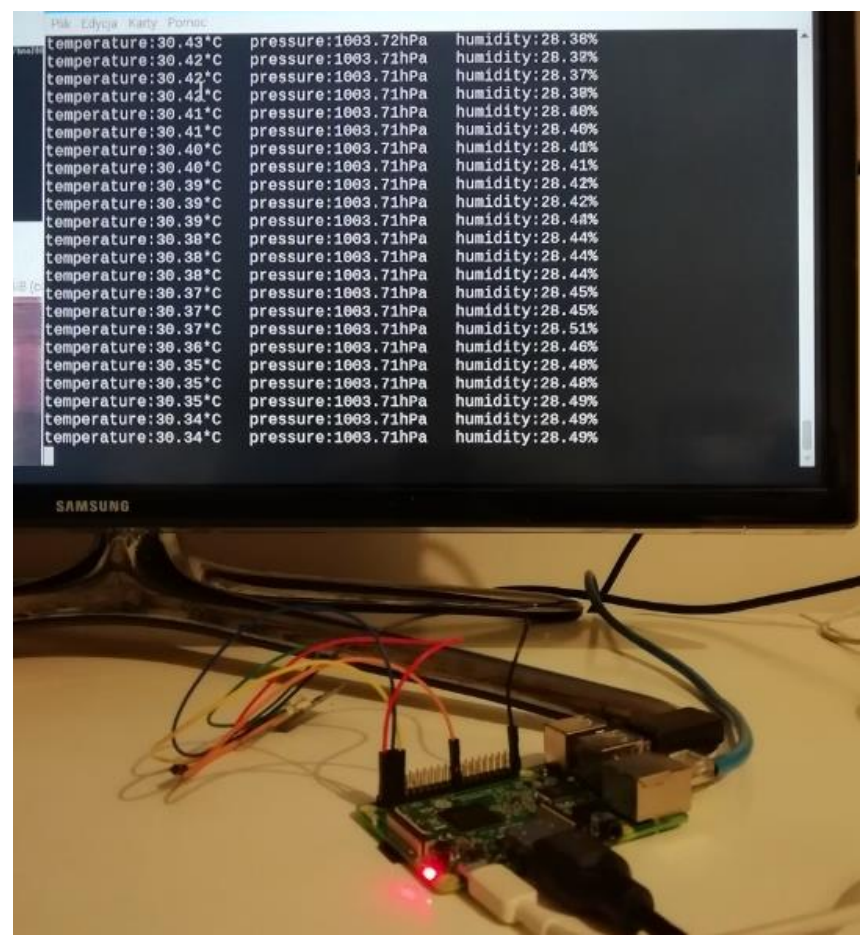

Figure 6. BME280 sensor measurement ready

The next step was connecting the second sensor, i.e. the DS18B20 probe, thanks to which the water temperature values were obtained. A contact plate was needed to connect the sensor to the microcomputer (as in Fig. 7). The probe, unlike the BME280 sensor, uses a GPIO interface, thanks to which we can connect both sensors to the device at the same time.

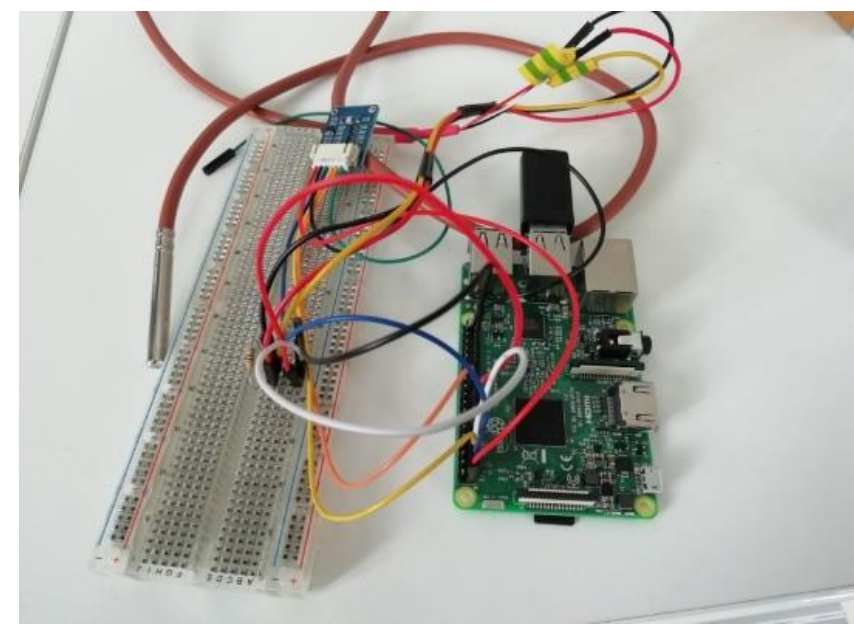

Figure 7. DS18B20 sensor connected to the contact plate

The code had to be programmed to get the results of the water temperature measurement. Here, simple code based on the previously presented Python programming language was used. It is much simpler than the sensor presented earlier, but the obtained result is displayed only once after entering the command.

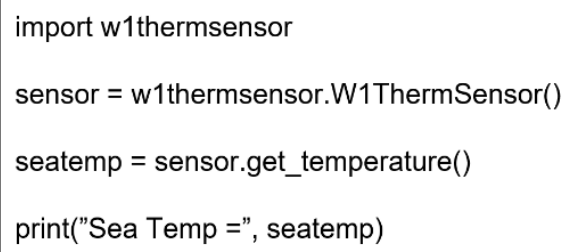

Figure 8. Code for DS18B20 sensor

Therefore, it is necessary to develop and combine both scripts to create one unified code, thanks to which all measurements can be displayed on one screen. In addition, the values displayed by both sensors should be named accordingly, which is why in the next stage I used the following words for the parameters:

- Air temperature - air temperature

- Sea temperature - water temperature

- Pressure - atmospheric pressure

- Relative humidity

The values presented by the sensors on the final display will be rounded to one decimal place and will be displayed after calling the commands. The values displayed continuously by the BME280 sensor will slow down the microcomputer's operation by limiting its RAM memory for a longer time. If the sensors are to provide data to the microcomputer, it is important that they are current and shown immediately after calling the command under the button on the display. Any slowdown or stopping the system can cause imaging of unreal measurement results. It is therefore important to create a code and a way to visualize the results so simple that it does not affect the negative operation of the microcomputer.

The first part necessary to create the report is to determine how the code reads the data from the sensor. In the BME280 manual you can find the code snippet responsible for this task. The code loading such data based on the sensor instruction was used. Data are taken from the sensor address in the system.

\section{PROPOSED DESIGN IMPROVEMENT AND OTHER POSSIBLE USES OF THE RASPBERRY PI MICROCOMPUTER}

The project has many options for improvement. One option is to create a barograph on the microcomputer display. It could be based on creating a small database with weather data. The system would download the data in the background and save it to the database at a 15-minute interval. The data would operate in the database for 24 hours and then be deleted to minimize the size of the database. The system would use the collected data to create an atmospheric pressure graph over a three-, six- and twelve-hour range. The electronic barometer indicated above has a similar application, however, assuming this thesis, all sensors and meteorological data will be displayed on one screen, therefore it would be necessary to develop such a database and create a program displaying the graph. [13]

In addition to the meteorological station, the microcomputer could be found on a ship in many 
other solutions. The first is to create a training station for officers and crew. XBMC software could do this. A computer connected to a monitor or TV would play training materials during weekly / monthly exercise alerts that are mandatory in accordance with SOLAS convention and flag State regulations.

Raspberry $\mathrm{Pi}$ could also be used to create a navigation station for lifeboats. Its small size, low power consumption and the ability to connect a USB device to it allows you to create a geographical position display of the ship. For construction it would be necessary to use a small LCD display and a GPS receiver connected via a USB port (see Fig. 9.). This solution would allow the unit's position to be determined and to navigate safely to the mainland.

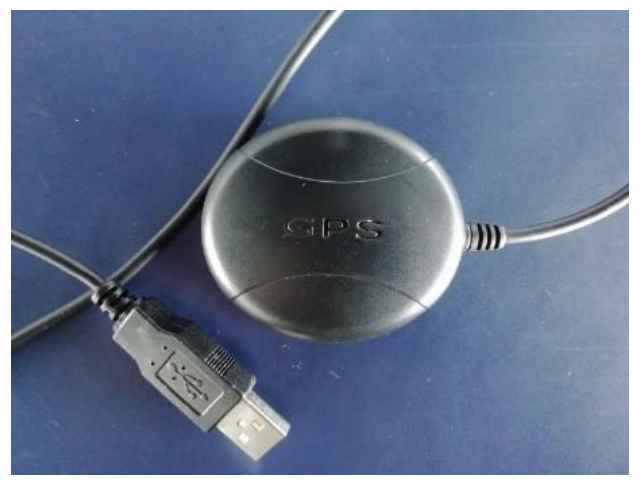

Figure 9. GPS receiver with USB plug

Another possibility of using such a microcomputer is to create from it a spare computer with a library of materials, instructions, procedures and important ship documents, which could be used during emergency situations, such as power loss. As it was presented earlier, the power consumption of this device is minimal, so that the batteries available on the ship could last much longer than when operating on desktop computers. In addition, its size and the ability to connect a portable screen allows it to move with it across different parts of the ship.

There are many ideas for using a microcomputer. Currently, you can find many publications, both online and book, presenting the possible uses of the Raspberry Pi microcomputer. Some of them could also be used on merchant ships.

\section{CONCLUSION}

The meteorological station project created in this work can find its application on merchant ships. As shown in the paper, sensors available to each user can present measurement data with values comparable to those obtained by certified equipment intended for commercial ships.

This is not the only possible use of a microcomputer, Raspberry $\mathrm{Pi}$ is constantly being improved. In the future, its computing power may increase, and the amount and current consumption may decrease. Therefore, finding even better options for using such microcomputers is a matter of time.
Possible development of the device in the next phase will allow the creation of further measuring devices such as, among others, a barograph. Thanks to the current design, the most important devices will be located in one place and their values will be displayed on one screen located in one or many places on the ship. This will allow you to control the weather not only from the navigation rooms, but also from the office rooms and even crew cabins, which will be able to check the current weather conditions every day.

\section{REFERENCES}

[1] Corral-García, J.; González-Sánchez, J.-L.; PérezToledano, M.-Á. Evaluation of Strategies for the Development of Efficient Code for Raspberry Pi Devices. Sensors 2018, 18, 4066, doi:10.3390/s18114066.

[2] Morón, C.; Diaz, J.; Ferrández, D.; Saiz, P. Design, Development and Implementation of a Weather Station Prototype for Renewable Energy Systems. Energies 2018, 11, 2234, doi:10.3390/en11092234.

[3] Davies, H.; Bevan, S. A Consultative Approach to Charter Party Agreements Based on Virtual On Time Arrival. TransNav, the International Journal on Marine Navigation and Safety of Sea Transportation 2017, 11, 303-308, doi:10.12716/1001.11.02.13.

[4] Capraro, F.; Tosetti, S.; Rossomando, F.; Mut, V.; Vita Serman, F. Web-Based System for the Remote Monitoring and Management of Precision Irrigation: A Case Study in an Arid Region of Argentina. Sensors 2018, 18, 3847, doi:10.3390/s18113847.

[5] Chang, S.J.; Huang, C.H.; Chang, S.M. AIS-Assisted Service Provision and Crowdsourcing of Marine Meteorological Information. TransNav, the International Journal on Marine Navigation and Safety of Sea Transportation 2019, 13, 63-67, doi:10.12716/1001.13.01.05.

[6] Jurdziński, M. Nawigacja morska; Akademia Morska: Gdynia, Polska, 2014; ISBN 978-83-7421-217-5.

[7] Neumann, T. Telematic Support in Improving Safety of Maritime Transport. TransNav, the International Journal on Marine Navigation and Safety of Sea Transportation 2018, 12, 231-235, doi:10.12716/1001.12.02.02.

[8] Carloni, A.; Baronti, F.; Di Rienzo, R.; Roncella, R.; Saletti, R. Open and Flexible Li-ion Battery Tester Based on Python Language and Raspberry Pi. Electronics 2018, 7, 454, doi:10.3390/electronics7120454.

[9] Halfarcree, G. The official Raspberry Pi Beginner's Guide; Raspberry Pi Press: Cambridge, 2018;

[10] Upton, E.; Halfacree, G. Raspberry Pi User Guide; John Wiley \& Sons Ltd: Chichester, 2012;

[11] Suehle, R.; Callaway, T. Raspberry Pi Hacks; O'Reilly Media Inc.: Sebastopol, California, 2014;

[12] Fernández-Cerero, D.; Fernández-Rodríguez, J.Y.; Álvarez-García, J.A.; Soria-Morillo, L.M.; FernándezMontes, A. Single-Board-Computer Clusters for Cloudlet Computing in Internet of Things. Sensors 2019, 19, 3026, doi:10.3390/s19133026.

[13] Stępień, B. Analysis and the possibility of using the Raspberry Pi microcomputer on the ship, engineering thesis, Gdynia Maritime University, Gdynia 2019

[13] Neumann, T. Automotive and Telematics Transportation Systems. In Proceedings of the 2017 International Siberian Conference on Control and Communications (SIBCON); IEEE: Astana, Kazakhstan, 2017; pp. 1-4. 